\title{
Intravascular Papillary Endothelial Hyperplasia of the Orbit: A Case of Masson's Tumor
}

\author{
Stephen C. Dryden ${ }^{1}$, Shane Marsili ${ }^{2}$, Andrew G. Meador ${ }^{1}$, M. Barry Randall ${ }^{3}$, Brian Fowler ${ }^{1}$ \\ 1. Ophthalmology, University of Tennessee Health Science Center, Memphis, USA 2. Ophthalmology, University of \\ Nevada, Reno School of Medicine, Reno, USA 3. Dermatology and Pathology, University of Tennessee Health Science \\ Center, Memphis, USA
}

Corresponding author: Shane Marsili, marsilis@med.unr.edu

\begin{abstract}
Herein, we present a case of a 64-year-old male presenting with diplopia that was found to have a left orbital Masson's tumor. It is necessary to differentiate it from malignant angiosarcoma as complete excision is often curative. The following case emphasizes the modalities that can be used for diagnosis as well as the appropriate treatments.
\end{abstract}

Categories: Ophthalmology, Oncology

Keywords: masson's tumor, ipeh, intravascular papillary endothelial hyperplasia, ophthalmology, oculoplastics, oncology, oncological surgery

\section{Introduction}

Masson's tumor, also known as intravascular papillary endothelial hyperplasia (IPEH), is a rare benign neoplasm that affects the head, neck, and upper extremities. There are few (less than 20) periorbital cases that have been reported in ophthalmologic literature [1-4]. Masson's tumor can often be difficult to distinguish between other entities including malignant angiosarcoma; its prompt diagnosis is important to begin optimal treatment as soon as possible.

\section{Case Presentation}

A 63-year-old Caucasian male with past medical history of diabetes mellitus and past ocular history of bilateral cataract extraction with intraocular lens (CEIOL) presented to an outside vitreoretinal specialist one-month post-CEIOL due to diplopia and possible retinal detachment. Best corrected visual acuity (BCVA) was measured as 20/25 OU, pupils were reactive without afferent pupillary defect (APD) OU, and intraocular pressure (IOP) was measured as 21 and $18 \mathrm{mmHg}$, respectively. Optical coherence tomography of both eyes revealed a flat and attached macula OU. Fundus photos revealed irregular appearance of nasal retina OS. The patient was subsequently diagnosed with nasal choroidal effusion and was given cyclopentolate, prednisolone, and oral dexamethasone.

Received 11/19/2019

Review began 11/28/2019 Review ended 11/29/2019 Published 12/01/2019

๑) Copyright 2019

Dryden et al. This is an open access article distributed under the terms of the Creative Commons Attribution License CC-BY 3.0., which permits unrestricted use, distribution, and reproduction in any medium, provided the original author and source are credited.
The patient returned for follow-up one week later with no resolution of symptoms and new complaint of an inferior "knot" OS with pain and pressure. BCVA and pupillary examination were unchanged. IOP was measured as 16 and $18 \mathrm{mmHg}$, respectively. Dilated fundoscopic examination was performed, and treatment was discontinued as the choroidal effusion had resolved.

Further follow-up three weeks later revealed no change in subjective pain and pressure symptoms OS. The patient described his diplopia as horizontal and binocular. Further questioning revealed that his symptoms began two months ago after CEIOL. BCVA, pupillary examination, and IOP were unchanged. Dilated fundoscopic examination was notable for a return of his choroidal effusion. MRI of the orbits with and without contrast ordered which revealed an enhancing $2.5 \times 1.6 \times 3.2 \mathrm{~cm}$ left orbital lesion involving both the intraconal and extraconal compartments and contributing to the left-sided proptosis (Figures 1-3). 


\section{Cureus}

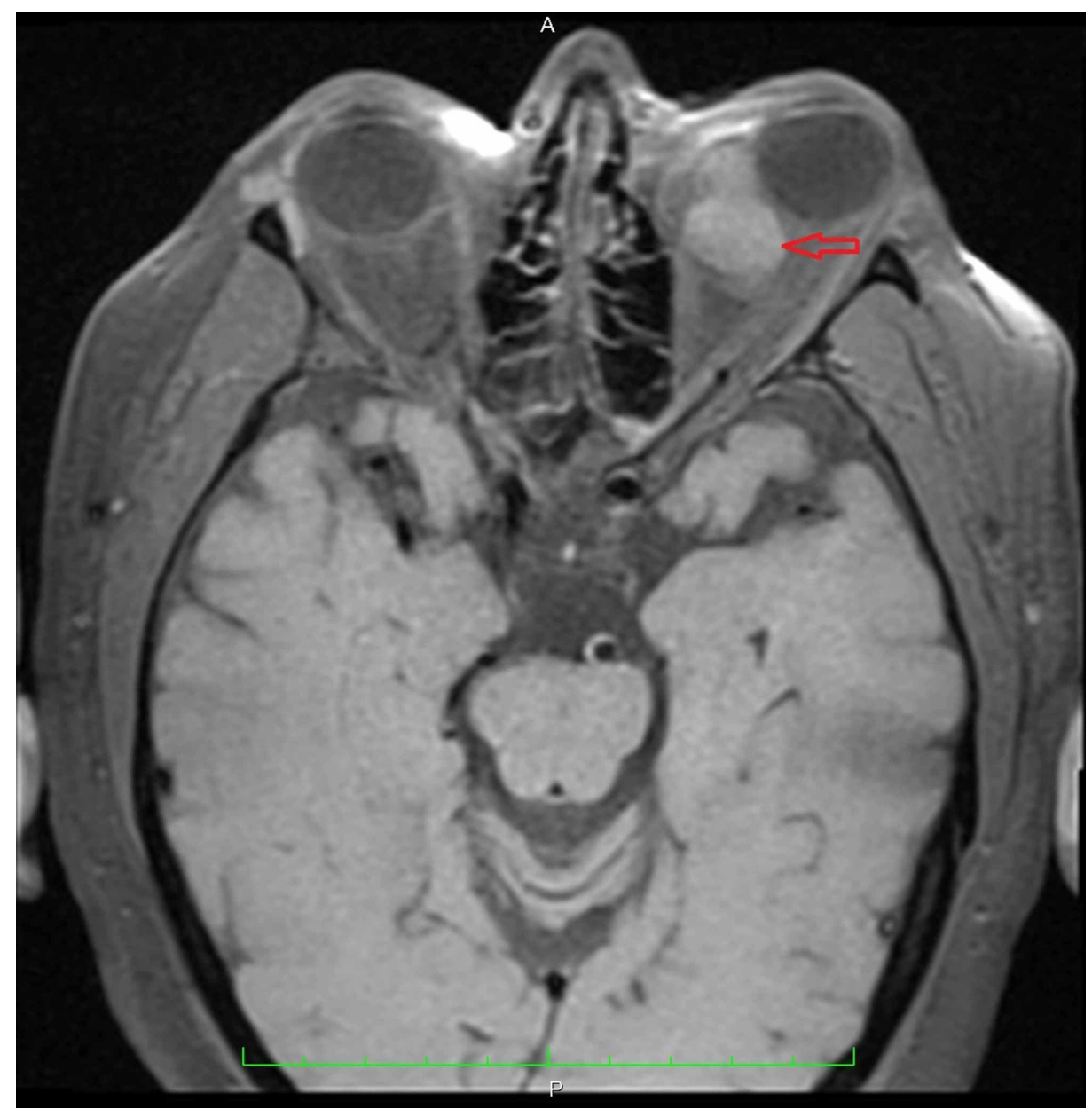

FIGURE 1: Transverse MRI of the orbits without contrast revealed a mass in the left orbit contributing to proptosis 


\section{Cureus}

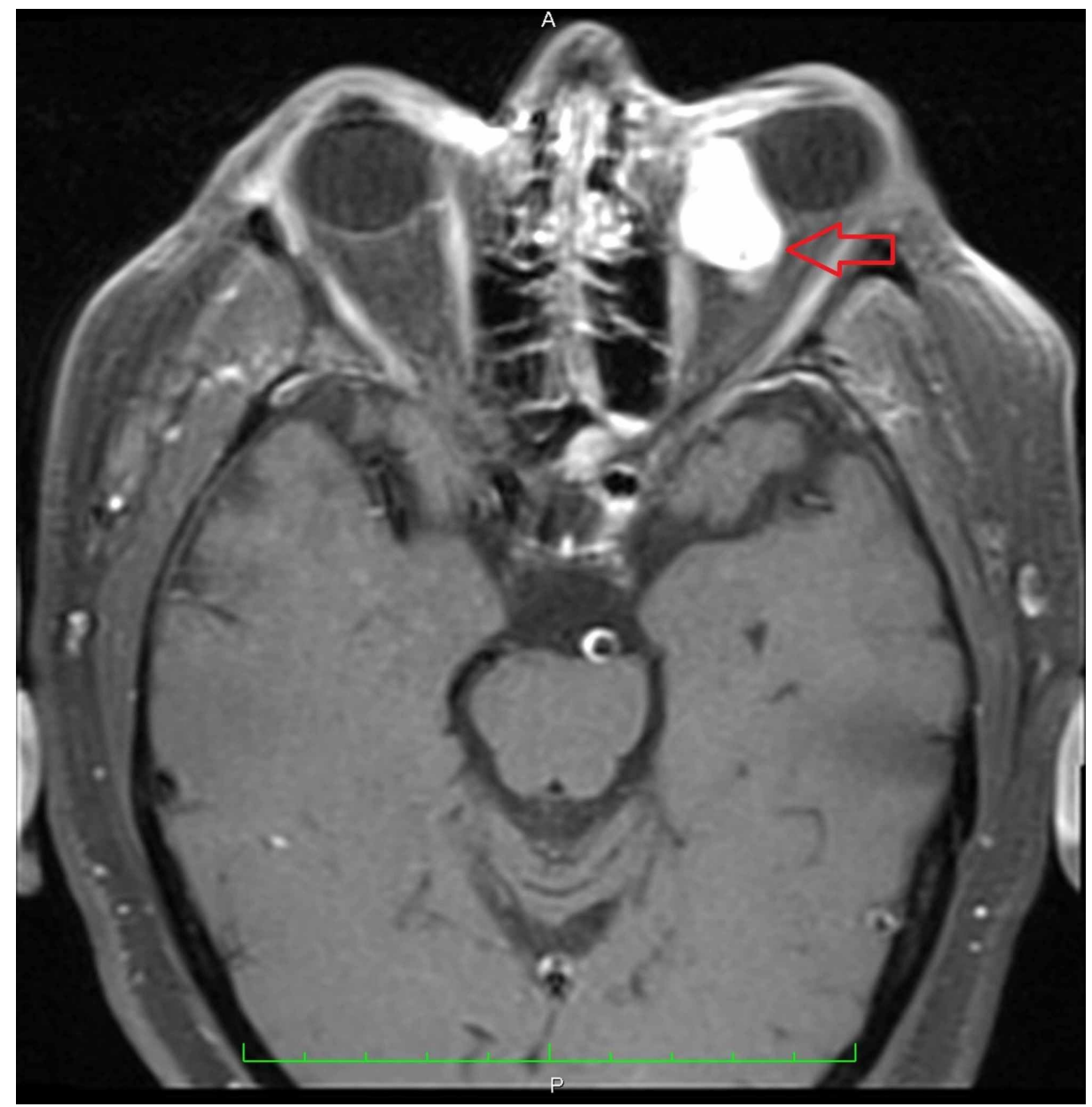

FIGURE 2: Transverse MRI of the orbits with contrast revealed an enhancing lesion in the left orbit involving both the intraconal and extraconal compartments measuring $2.5 \times 1.6 \times 3.2 \mathrm{~cm}$ 


\section{Cureus}

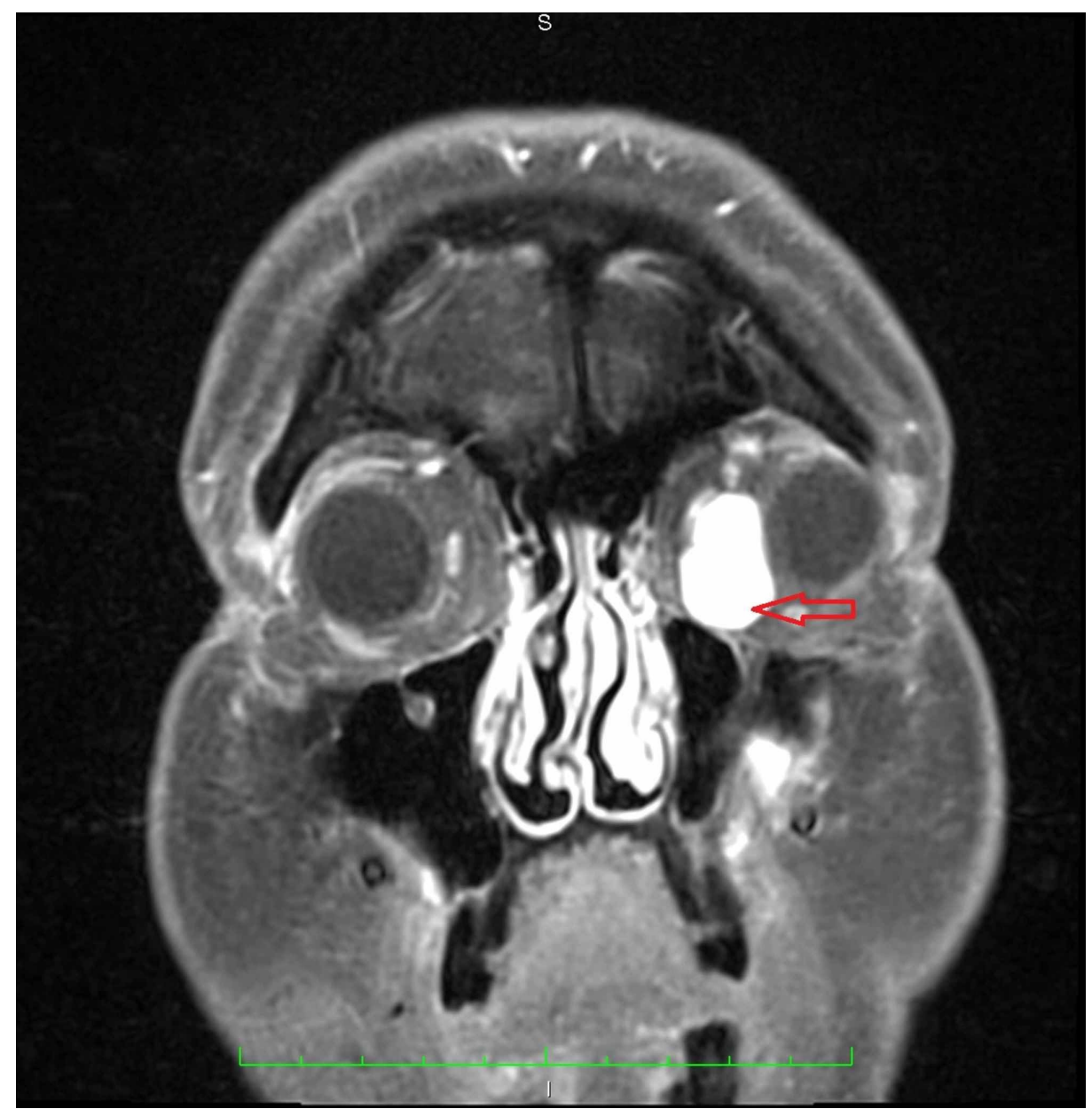

FIGURE 3: Coronal MRI of the orbits with contrast gives another view of the enhancing lesion within the left orbit

At this time, the patient was referred to oculoplastics for further evaluation. Nineteen days after the MRI, the patient reported continued diplopia, pain, and proptosis OS. His ocular examination was as follows: BCVA of 20/25 OU, pupils reactive with no APD OU, IOP of 21 and $27 \mathrm{mmHg}$, respectively. His extraocular movements were full OD and -1 in all gazes OS. His MRI was reviewed, and the patient was scheduled for a biopsy of the orbital mass. An approximately $2.1 \times 0.5 \mathrm{~cm}$ mass submitted for routine sectioning revealed papillary formations and arborizing channels contained within a fibromuscular wall compatible with a dilated vascular space. Variably sized vascular channels intersect the interior of the mass, and these channels contain erythrocytes and serum. Papillae are characterized by a hyalinized fibrovascular core lined by plump mononuclear cells that occasionally form syncytia. CD31 immunohistochemical marker for endothelial cells richly outlines the furcating vascular network (Figures 4-7). 


\section{Cureus}

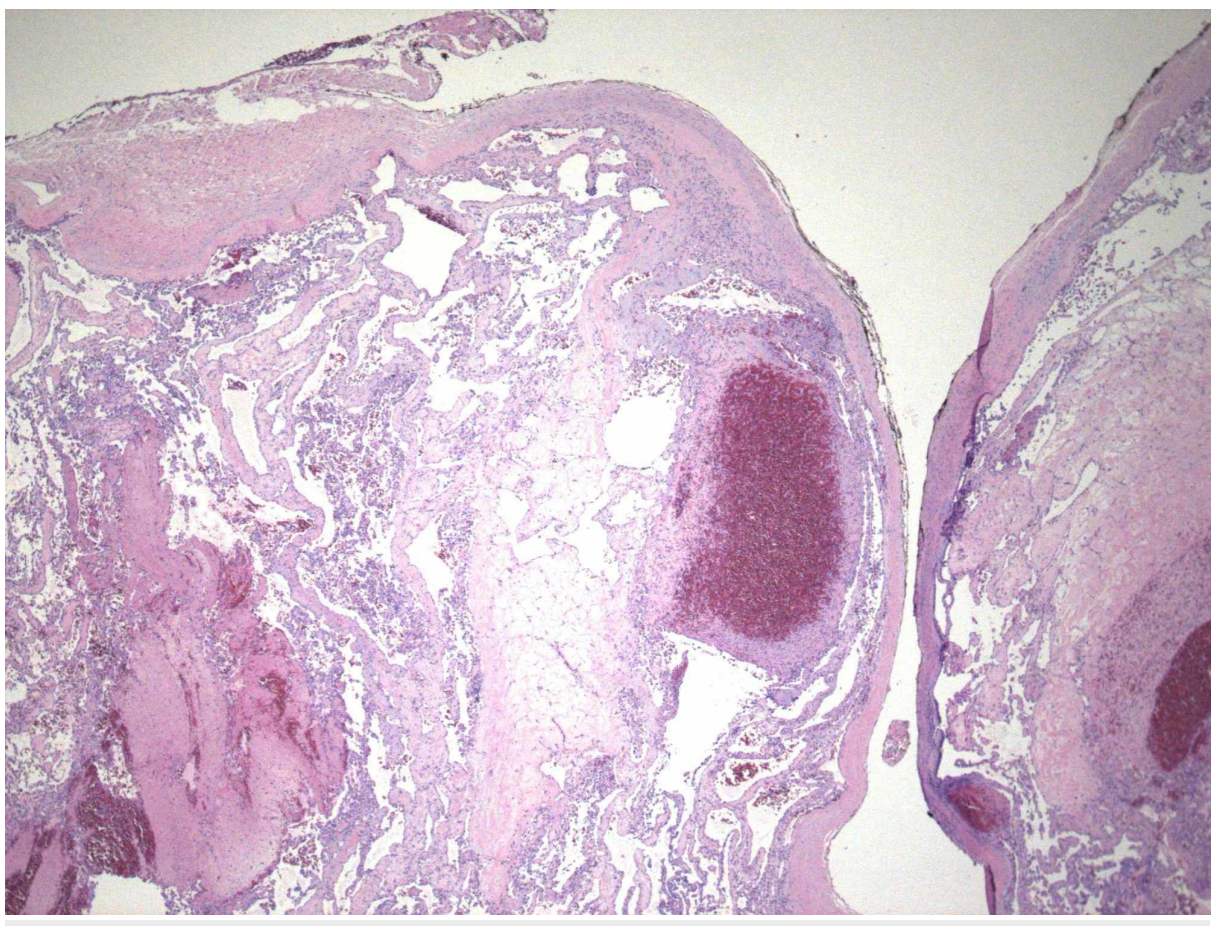

FIGURE 4: The absence of tissue necrosis, noninfiltrative intraluminal location of the lesion, and the association between proliferating tuft structures with thrombotic material differentiate IPEH from angiosarcoma

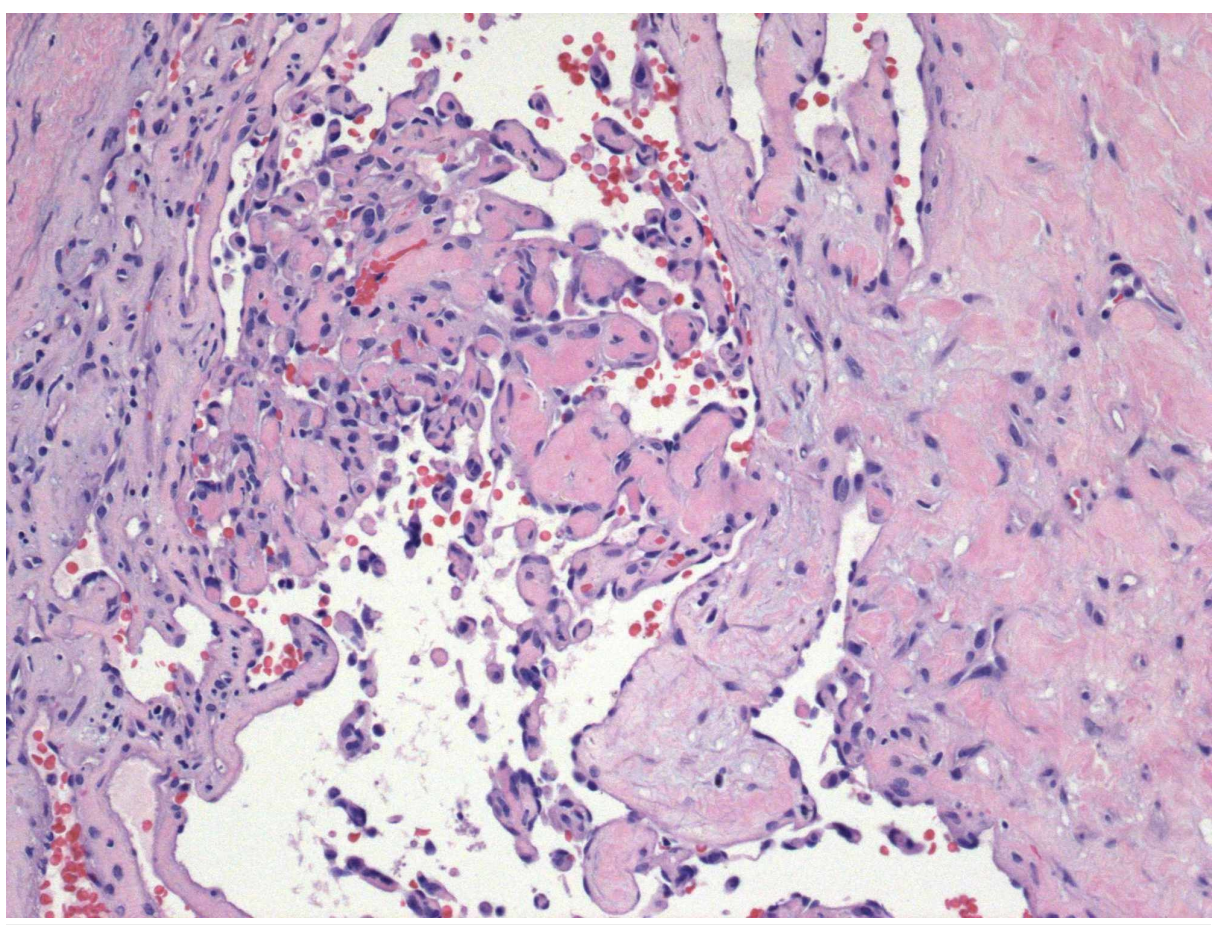

FIGURE 5: Papillary formations and arborizing channels 


\section{Cureus}

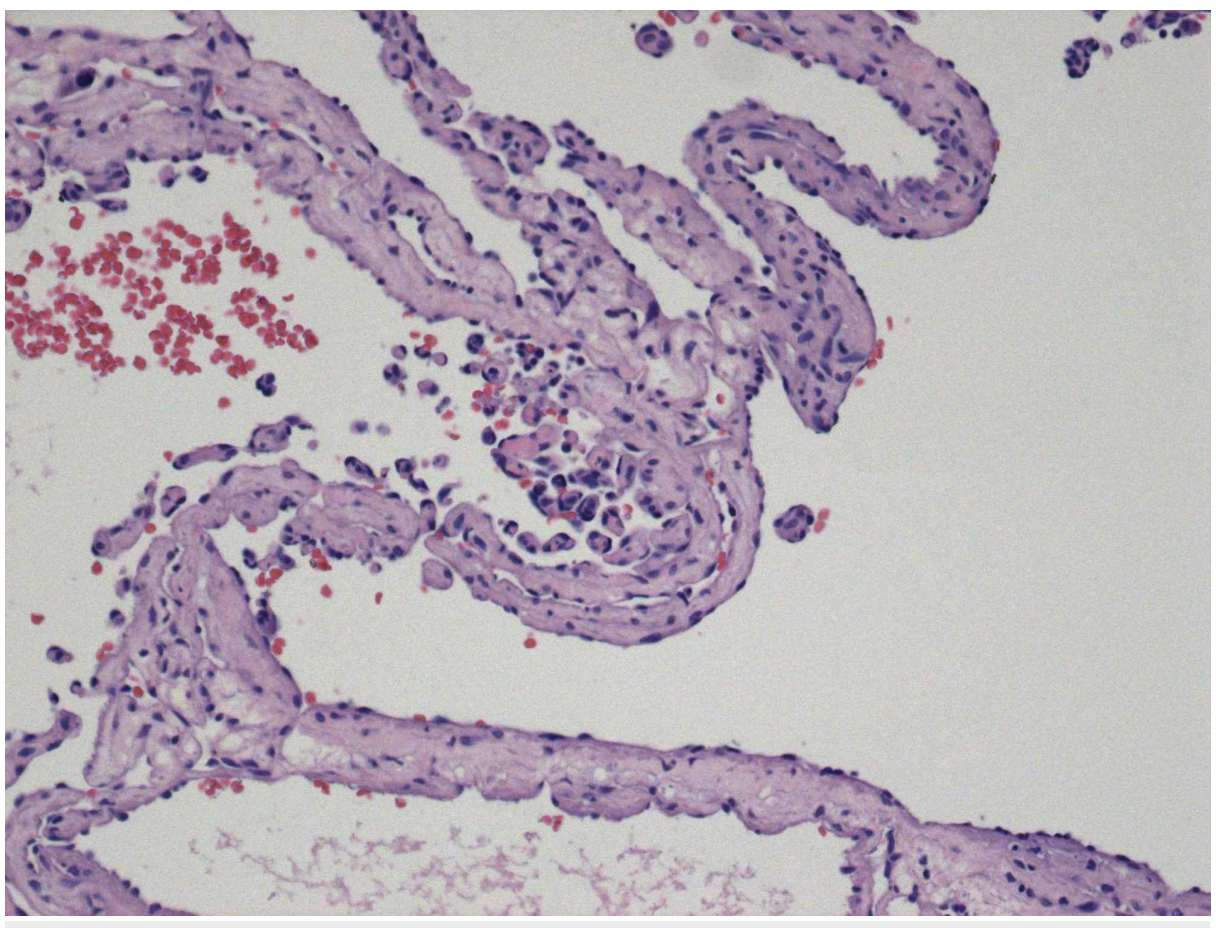

FIGURE 6: Vascular channels containing erythrocytes and serum

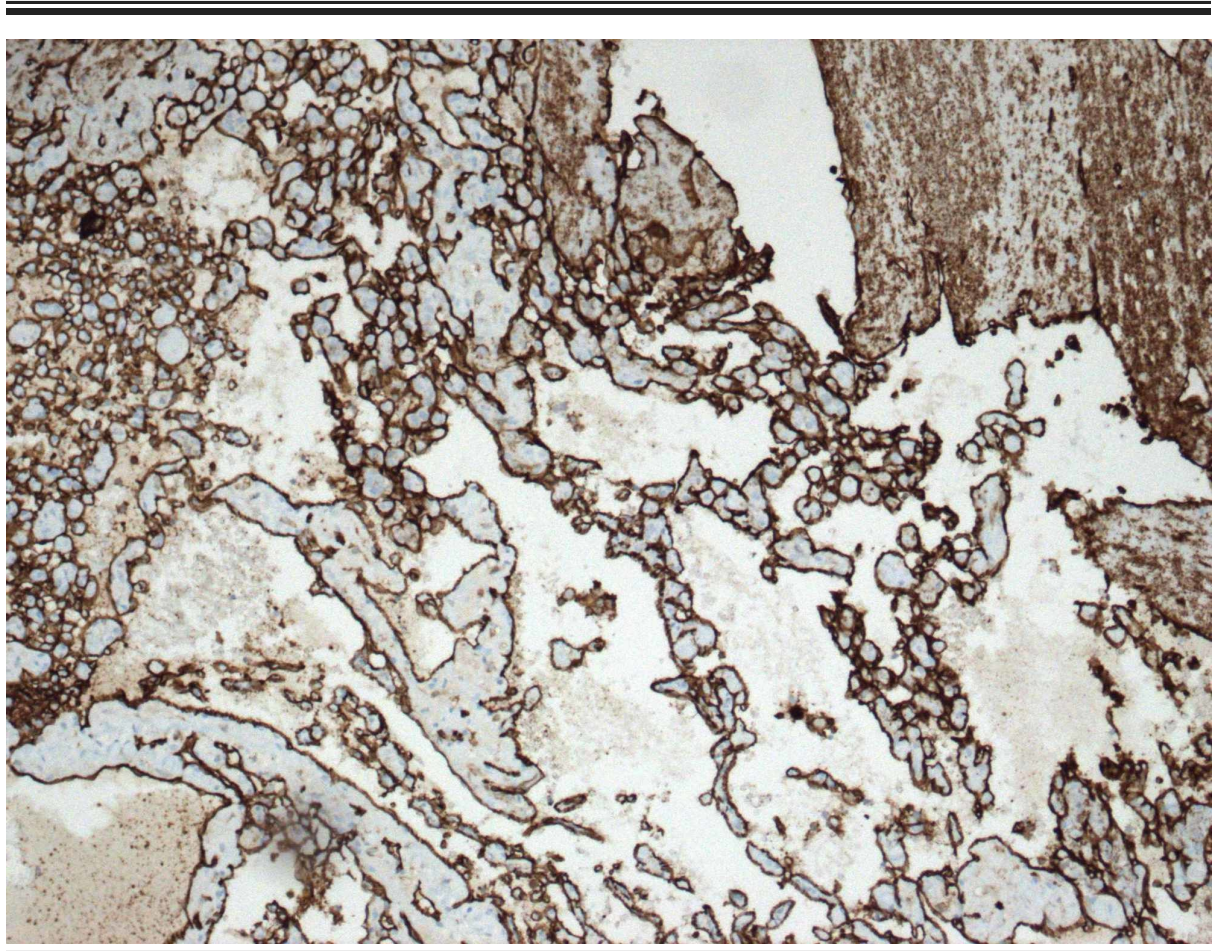

FIGURE 7: CD31 immunohistochemical marker

The final diagnosis was IPEH, also known as Masson's tumor.

The patient subsequently underwent orbitotomy with excision with removal of approximately $80 \%$ of the tumor. The other $20 \%$ was inaccessible as it was circumferential to the optic nerve. The patient had improvement of pain, diplopia, and proptosis post-surgery, and a follow-up CT was scheduled three months later.

\section{Discussion}


IPEH was first described by Masson in 1923 as “vegetate intravascular hemangioendothelioma” [5]. It is characterized by a reactive hyperplastic proliferation of the vascular endothelium [1]. It has been speculated that the primary process is endothelial proliferation followed by thrombus formation; however, others conjecture that endothelial papillary proliferation is a response to thrombus formation [1-3]. There is no age, race, or sex predilection for the generalized IPEH; however, in their case series, Wagh et al found that the average age for periorbital IPEH was 41.2 years with a male to female ratio of $2: 1$ [1,2].

IPEH has a predisposition for the head, neck, and upper extremities, and it may present in both the orbit and eyelid. It often presents as a firm, cystic, freely mobile, reddish/purple swelling that may increase in size $[3,4]$. The differential diagnosis of IPEH includes vascular lesions such as angiosarcoma, angiolymphatic hyperplasia with eosinophilia (Kimura disease), and other primary or secondary tumors $[1,2,6]$. The histopathologic absence of tissue necrosis, noninfiltrative intraluminal location of the lesion, and the association between proliferating tuft structures with thrombotic material help to differentiate IPEH from angiosarcoma [1,7]. It needs to be differentiated from malignant angiosarcoma as complete excision is often curative [8].

There are three forms of IPEH. Primary IPEH forms within a dilated vascular space with a preference for extremities. Secondary or reactive IPEH is the most common and is predominately found in the musculature. It originates within pre-existing vascular malformations such as varix, lymphangioma, or cavernous hemangioma. Tertiary IPEH is the rarest, forms within hematomas, and is extravascular.

Evidence of unilateral proptosis in an elderly patient should prompt imaging to rule out mass effect. MRI is the preferred imaging technique for identifying IPEH. Lesions appear isointense on T1-weighted imaging and hyperintense on T2-weighted imaging with homogenous enhancement following contrast administration [1]. Management depends on the clinical features and progression of the lesion. Surgical excision is the preferred method of treatment; however, the lesion may recur with incomplete excision. There may be a role for adjuvant chemotherapy and radiotherapy for recurrent or concerning lesions [1-3].

\section{Conclusions}

Recognizing IPEH and differentiating from malignant lesions such as angiosarcoma is important to prevent morbidity related to unnecessary chemotherapy, radiation, and surgery. This case emphasizes the importance of early diagnosis and a strong referral base for appropriate diagnosis and treatment. Even in cases where surgical correction is not entirely curative, a significant improvement of symptoms can be obtained post-surgery. This patient received appropriate care and surgical correction to remove $80 \%$ of the tumor, and he subsequently had significant quality-of-life improvements.

\section{Additional Information \\ Disclosures}

Human subjects: Consent was obtained by all participants in this study. Conflicts of interest: In compliance with the ICMJE uniform disclosure form, all authors declare the following: Payment/services info: All authors have declared that no financial support was received from any organization for the submitted work. Financial relationships: All authors have declared that they have no financial relationships at present or within the previous three years with any organizations that might have an interest in the submitted work. Other relationships: All authors have declared that there are no other relationships or activities that could appear to have influenced the submitted work.

\section{References}

1. Wagh VB, Kyprianou I, Burns J, Brown LJR, Vaidhyanath R, Sampath R: Periorbital masson's tumor: a case series. Ophthalmic Plast Reconstr Surg. 2010, 27:55-57. 10.1097/IOP.0b013e3181e978f4

2. Werner MS, Hornblass A, Harrison W, Reifler DM, Dresner SC: Intravascular papillary endothelial hyperplasia: collection of four cases and a review of the literature. Ophthalmic Plast Reconstr Surg. 1997, 13:48-56. 10.1097/00002341-199703000-00009

3. Aggarwal E, Madge SN, Selva D, Rodgers N: Compressive effects of intravascular papillary endothelial hyperplasia. Ophthalmic Plast Reconstr Surg. 2010, 26:122-124. 10.1097/IOP.0b013e3181b8e0e9

4. Zakka FR, Jakobiec FA, Thakker MM: Eyelid varix with phlebolith formation, thrombus recanalization, and early intravascular papillary endothelial hyperplasia. Ophthalmic Plast Reconstr Surg. 2011, 27:8-11. 10.1097/IOP.0b013e3181d8e13c

5. Masson MP: Hemangioendotheliome vegetant intravasculare. Bull Soc Anat. 1923, 93:517.

6. Shields JA, Shields CL, Eagle RC Jr, Diniz W: Intravascular papillary endothelial hyperplasia with presumed orbital varices. Arch Ophthalmol. 1999, 117:1247-1249.

7. Clearkin KP, Enzinger FM: Intravascular papillary endothelial hyperplasia . Arch Pathol Lab Med. 1976, 100:441-444.

8. Salyer WR, Salyer DC: Intravascular angiomatosis: development and distinction from angiosarcoma . Cancer. 1975, 36:995-1001. 10.1002/1097-0142(197509)36:3<995::AID-CNCR2820360323>3.0.CO;2-B 